ORIGINAL ARTICLE

\title{
Trends in hospitalization after injury: older women are displacing young men
}

\section{T Shinoda-Tagawa, D E Clark}

\begin{abstract}
Objective: To evaluate trends in hospitalization after injuries in the USA.
Design: National Hospital Discharge Survey data from 1979 to 2000 were evaluated annually by age group, sex, injury severity score (ISS), length of stay, and discharge destination.

Setting and subjects: National probability sample of hospitalized patients. Interventions: None.

Main outcome measures: Incidence, duration, outcome, and population based rates of hospital admission after injuries.

Results: The number of young males admitted to hospitals after injuries has decreased dramatically; older females are now the group most frequently admitted. Total days in the hospital have decreased in all age groups, but have declined less in the older population than in the younger population; furthermore, most patients aged 65 and over were formerly discharged home, but now most are discharged to long term care facilities. Overall hospitalization rates after injury have decreased in all age groups, but have declined less in the older population; furthermore, male and female hospitalization rates for serious injury (ISS at least 9, excluding isolated hip fracture) are decreasing in younger age groups while increasing in older age groups.

Conclusions: Older patients comprise a growing proportion of injuries requiring hospitalization. Trauma systems must address this change, and preventing injuries in older people is increasingly important.
\end{abstract}

See end of article for authors' affiliations
Correspondence to: Dr David E Clark, 887 Congress Street Suite 210, Portland, ME 04102, USA; clarkd@mmc.org wo decades ago, injury was recognized as significant public health problem for the young, especially for young males. ${ }^{1}$ However, an increasing proportion of the patients cared for by trauma systems are now older. ${ }^{2}$ The purpose of this study was to evaluate national trends in hospitalization related to injury. These findings have major implications for the structure and financing of trauma care systems, as well as identifying priorities for injury prevention.

\section{METHODS}

National Hospital Discharge Survey (NHDS) data for 19792000 were obtained on a compact disk from the Centers for Disease Control and Prevention (CDC) and from the web site of the CDC. ${ }^{3}$ NHDS is a national probability sample of discharge data from acute care general hospitals in the United States conducted annually by the CDC. ${ }^{4}$ NHDS used a two stage design (a random sample of hospitals and then a random sample of discharges from selected hospitals) until 1987, and has used a three stage design (adding an additional regional level of sampling) since that time. NHDS data include patient age and sex, up to seven International Classification of Diseases, ninth revision, clinical modification (ICD-9-CM) diagnosis codes, and hospital outcomes (including death or discharge destination). Estimates of national totals can be obtained by weighting according to the inverse of the case selection probability.

From the raw data, cases for this study were selected if their principal ICD-9-CM diagnosis code was in the range of injury (800-959), excluding late effects of injury (905-909), foreign bodies (930-939), and complications (958). Commercially available software (ICDMAP-90, Tri-Analytics, Baltimore, $\mathrm{MD}$ ) mapped each diagnosis code to one of six body regions and six levels of abbreviated injury score (AIS) when possible, then calculated an overall injury severity score (ISS). ${ }^{56}$ The "ignore unknown" and "low severities" options for the software were used, thus ignoring any ICD-9-CM code that could not be classified and selecting the less severe AIS where this mapping was equivocal. Estimates of totals, means, rates, and proportions were calculated according to methods that accounted for weighted survey data (using Stata version 7, College Station, Texas).

Fractures of the femoral neck (hip) comprise a large proportion of the injury admissions over the age of 65 , but very few of those under the age of 65 , and were therefore considered as a special group. Cases were classified into four categories: (1) isolated hip fracture (ICD-9- CM principal diagnosis codes 820.0-820.9, with ISS =9); (2) other serious injuries (ISS at least 9); (3) moderate injuries (ISS <9); and (4) injuries of undetermined severity (where ISS could not be calculated by ICDMAP-90). External cause of injury codes (E codes) were also sought among the diagnosis codes, and if present were classified as recommended by the CDC. ${ }^{7}$

In addition to the severity categories, patients were analyzed by year, sex, and the following age categories: 0-14, $15-19,20-39,40-64,65-74,75-84,85$ and older. For each subgroup, we determined the frequency of hospitalization, mechanisms of injury, total days of hospitalization, and frequency of discharge destination. Hospital destination categories included death, discharge to home (including those who left against medical advice), discharge/transfer to short term facilities (including rehabilitation centers), discharge/ transfer to long term care institutions, and other (including alive but not specified). In 1979 and 1980, a different categorization was used for discharge destinations; therefore, these

Abbreviations: AIS, abbreviated injury score; CDC, Centers for Disease Control and Prevention; ICD-9-CM, International Classification of Disease, ninth revision, clinical modification; ISS, injury severity score; NHDS, National Hospital Discharge Survey; SNF, skilled nursing facility 
Table 1 NHDS estimated annual numbers of patients hospitalized after injury, in thousands, for 1979-83 and 1996-2000; 95\% confidence intervals are given in parentheses

\begin{tabular}{|c|c|c|c|c|}
\hline & \multicolumn{2}{|l|}{ Male } & \multicolumn{2}{|l|}{ Female } \\
\hline & $1979-83$ & 1996-2000 & 1979-83 & 1996-2000 \\
\hline Total & $1670(1658$ to 1681$)$ & 781 (771 to 792) & 1201 (1190 to 1213$)$ & 788 (778 to 799 ) \\
\hline \multicolumn{5}{|l|}{ Age groups } \\
\hline $0-14$ & 243 (237 to 249 ) & 96 (91 to 101$)$ & 128 (124 to 133 ) & 51 (47 to 54$)$ \\
\hline $15-19$ & 219 (213 to 225$)$ & 67 (63 to 72$)$ & 86 (82 to 90$)$ & 27 (24 to 30$)$ \\
\hline $20-39$ & 701 (693 to 706) & 240 (234 to 247$)$ & 293 (287 to 300$)$ & 90 (85 to 94$)$ \\
\hline $40-64$ & 350 (343 to 357$)$ & 200 (193 to 206$)$ & 277 (270 to 283$)$ & $139(133$ to 145$)$ \\
\hline $65-74$ & 75 (71 to 78$)$ & $59(55$ to 64$)$ & $140(135$ to 145$)$ & 108 (103 to 114$)$ \\
\hline $75-84$ & $54(51$ to 57$)$ & 73 (69 to 78$)$ & 169 (164 to 175$)$ & 192 (185 to 198$)$ \\
\hline $85+$ & 28 (25 to 30$)$ & 45 (41 to 48$)$ & 107 (103 to 111$)$ & 182 (175 to 188$)$ \\
\hline \multicolumn{5}{|l|}{ Injury categories } \\
\hline Isolated hip fracture & 51 (48 to 54$)$ & 79 (75 to 84$)$ & 160 (155 to 166$)$ & 235 (228 to 242 ) \\
\hline Other serious injuries & 210 (205 to 216$)$ & 214 (208 to 221$)$ & 121 (116 to 125$)$ & 161 (155 to 167 ) \\
\hline Moderate injuries & 1335 (1328 to 1342$)$ & 469 (461 to 476 ) & 873 (866 to 879 ) & 377 (369 to 384 ) \\
\hline Undetermined injuries & $73(69$ to 77$)$ & $19(17$ to 21$)$ & $47(44$ to 50$)$ & 15 (13 to 17$)$ \\
\hline
\end{tabular}

Table 2 NHDS estimated annual rates of hospitalization per 100000 population after injury for 1979-83 and 1996-2000; 95\% confidence intervals are given in parentheses

\begin{tabular}{|c|c|c|c|c|}
\hline & \multicolumn{2}{|l|}{ Male } & \multicolumn{2}{|l|}{ Female } \\
\hline & $1979-83$ & 1996-2000 & 1979-83 & 1996-2000 \\
\hline Overall rate & 1498 (1488 to 1508 ) & 585 (578 to 593 ) & 1019 (1009 to 1029$)$ & 561 (554 to 569 ) \\
\hline \multicolumn{5}{|l|}{ Age groups } \\
\hline $0-14$ & 925 (901 to 949) & 314 (299 to 329) & 512 (493 to 530$)$ & 168 (157 to 179$)$ \\
\hline $15-19$ & 2102 (2044 to 2159 ) & 674 (632 to 715$)$ & 859 (819 to 898$)$ & 288 (259 to 316$)$ \\
\hline 20-39 & 1891 (1867 to 1914$)$ & 602 (585 to 618$)$ & 781 (763 to 798$)$ & 225 (213 to 237$)$ \\
\hline $40-64$ & 1290 (1263 to 1316$)$ & 517 (500 to 534$)$ & 937 (916 to 960$)$ & 342 (328 to 356$)$ \\
\hline $65-74$ & 1084 (1032 to 1136$)$ & $716(670$ to 763$)$ & $1557(1503$ to 1612$)$ & $1064(1010$ to 1118$)$ \\
\hline $75-84$ & 1827 (1721 to 1932$)$ & $1550(1451$ to 1648$)$ & 3364 (3260 to 3469 ) & 2660 (2571 to 2749 ) \\
\hline $85+$ & 3958 (3634 to 4281 ) & 3815 (3530 to 4101$)$ & 6487 (6226 to 6748$)$ & 6349 (6123 to 6575$)$ \\
\hline \multicolumn{5}{|l|}{ Injury categories } \\
\hline Isolated hip fracture & 46 (43 to 49$)$ & 59 (56 to 63) & 136 (132 to 140$)$ & 168 (163 to 173$)$ \\
\hline Other serious injuries & 189 (184 to 194$)$ & 161 (156 to 165$)$ & $102(98$ to 106$)$ & 115 (110 to 119$)$ \\
\hline Moderate injuries & 783 (777 to 789 ) & 351 (346 to 357$)$ & 740 (734 to 746$)$ & 268 (263 to 274$)$ \\
\hline Undetermined injuries & $65(62$ to 69$)$ & $14(13$ to 16$)$ & 40 (38 to 43$)$ & $11(9$ to 12$)$ \\
\hline
\end{tabular}

two years were excluded from this part of the analysis. National population figures for each age and sex category, including the military and institutionalized populations as appropriate, were also obtained from the CDC, ${ }^{8}$ and used to calculate annual population based rates of hospitalization for each subgroup.

\section{RESULTS}

The annual frequency of admissions to the hospital for different categories of age, sex, and severity are shown in table 1 and fig 1; population based rates are shown in table 2. Since the rates for ages 15-19 were very similar to the rates for ages 20-39, these groups have been combined for clarity in the graphs. The most striking change over the past two decades has been the absolute decrease in the number of young (aged 15-39) and middle aged (aged 40-64) men admitted to a hospital after injury (table 1 and fig 1). Males under 40 years of age accounted for $41 \%$ of hospital admissions after injury in 1979-83, but only $26 \%$ in 1996-2000. Women over the age of 65 now account for a larger proportion of admissions $(28 \%$ in 1996-2000), and the proportion of patients aged 75 and older more than doubled from 1979-83 to 1996-2000.

Some of these changes can be attributed to the increasing population of females aged 65 and older during the period between 1979 and 2000 (from 15.0 million to 20.6 million), but the number of males under 40 years of age is also somewhat larger (increasing from 72.3 million to 82.4 million). As shown in table 2, the hospitalization rates after injury have fallen by about $70 \%$ for both males and females aged $<15,15-19$, and 20-39, while the rates of hospitalization changed much less for older men and women. Hip fracture accounted for half of the hospitalizations among females aged 75 and older, and about $40 \%$ among males aged 75 and older. The number of hospitalizations for hip fracture has been steadily increasing for the older age groups, but the rates per 100000 population have been quite stable for ages $65-74$, ages 75-84, and ages 85 and older.

The total number of days in hospital for each category, which may be taken as a rough estimate of hospital cost, ${ }^{9}$ decreased in every age category (fig 2). The decrease for young men aged 15-39 has been most notable, while the decreases in younger or older age groups have been more moderate. The total number of days in hospitals after hip fracture is decreasing for older women, while it has been relatively constant for older men (not shown). If the analysis was restricted to injuries other than hip fracture, the total number of hospital days for older men and women has remained steady since 1988.

Although most younger patients are discharged home from the hospital, the discharge destination for older patients has changed dramatically over the past two decades. Figure 3 indicates a steady decrease in the frequency of discharge to home and a steady increase in the frequency of discharge to short term or long term care facilities (including rehabilitation centers and skilled nursing facilities). In 2000, 52\% of 


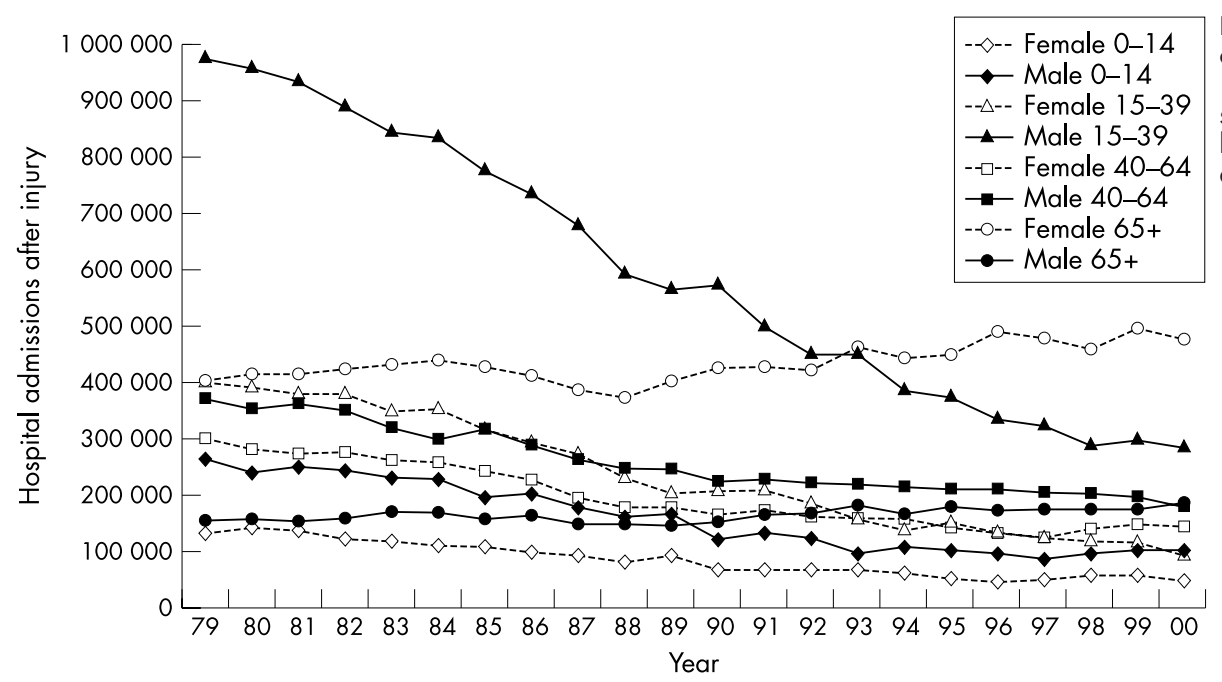

Figure 1 Estimated annual numbers of patients hospitalized after injury, 1979-2000, grouped by age and sex. Male groups shown with solid lines and female groups shown with dashed lines.
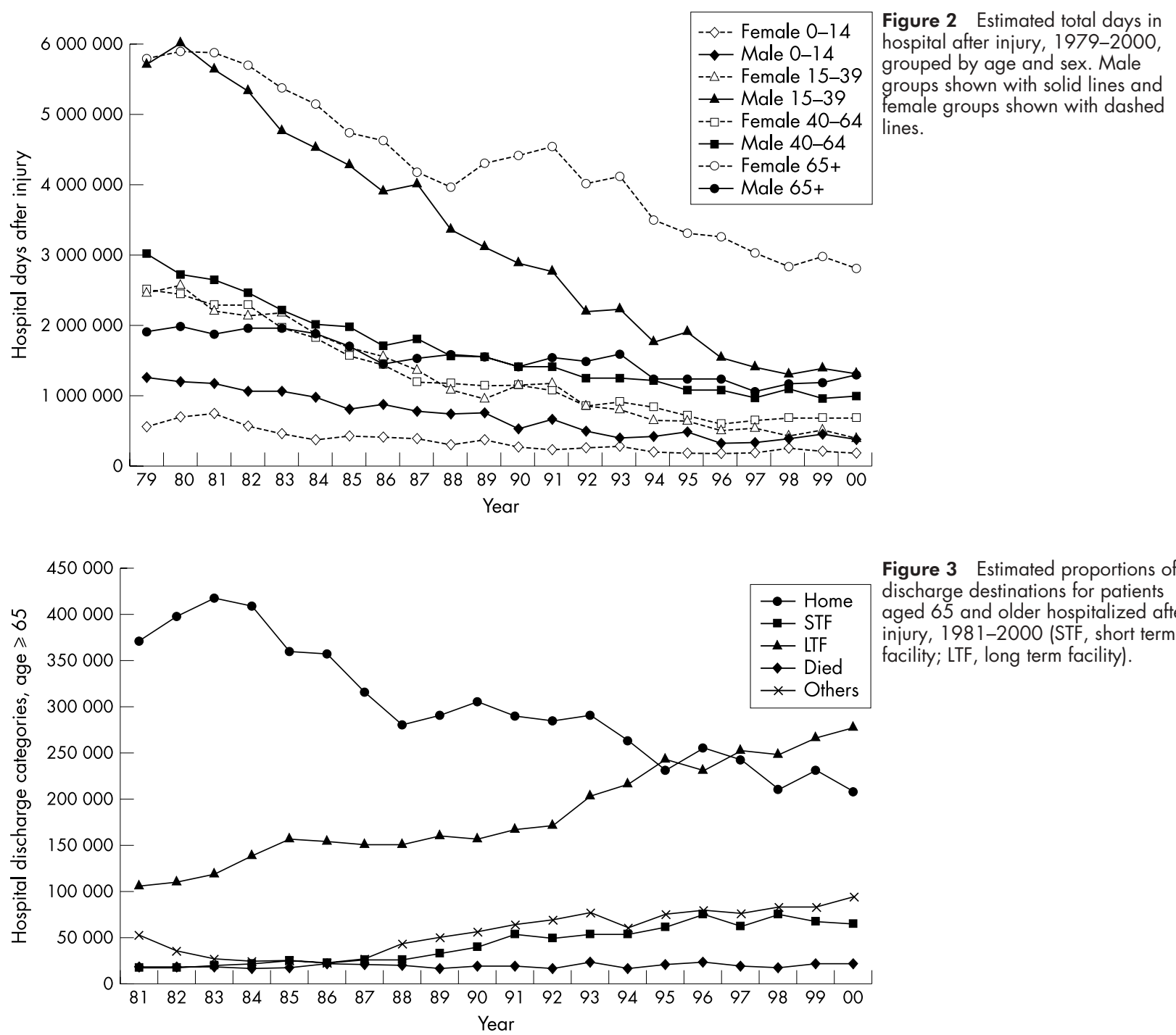

Figure 3 Estimated proportions of discharge destinations for patients aged 65 and older hospitalized after injury, 1981-2000 (STF, short term facility; LTF, long term facility).

patients aged 65 and older were discharged to short term and long term care facilities after hospitalization for injuries and $31 \%$ were discharged home, compared with $22 \%$ and $66 \%$, respectively, in 1981. If the analysis was limited to hip fractures in 2000, long term care facilities account for $56 \%$ of all discharge destinations in this age group, while only 13\% went directly back to the community. Conversely, for injuries other than hip fracture, $31 \%$ were transferred to long term care facilities and $45 \%$ went home.

Figures $4 \mathrm{~A}$ and $4 \mathrm{~B}$ depict the rate of admissions for other serious injuries (ISS at least 9, after excluding isolated hip fractures), which would rarely be treated without hospitalization, stratified by age and sex. The rate of hospitalization for these serious injuries decreased among males and females 

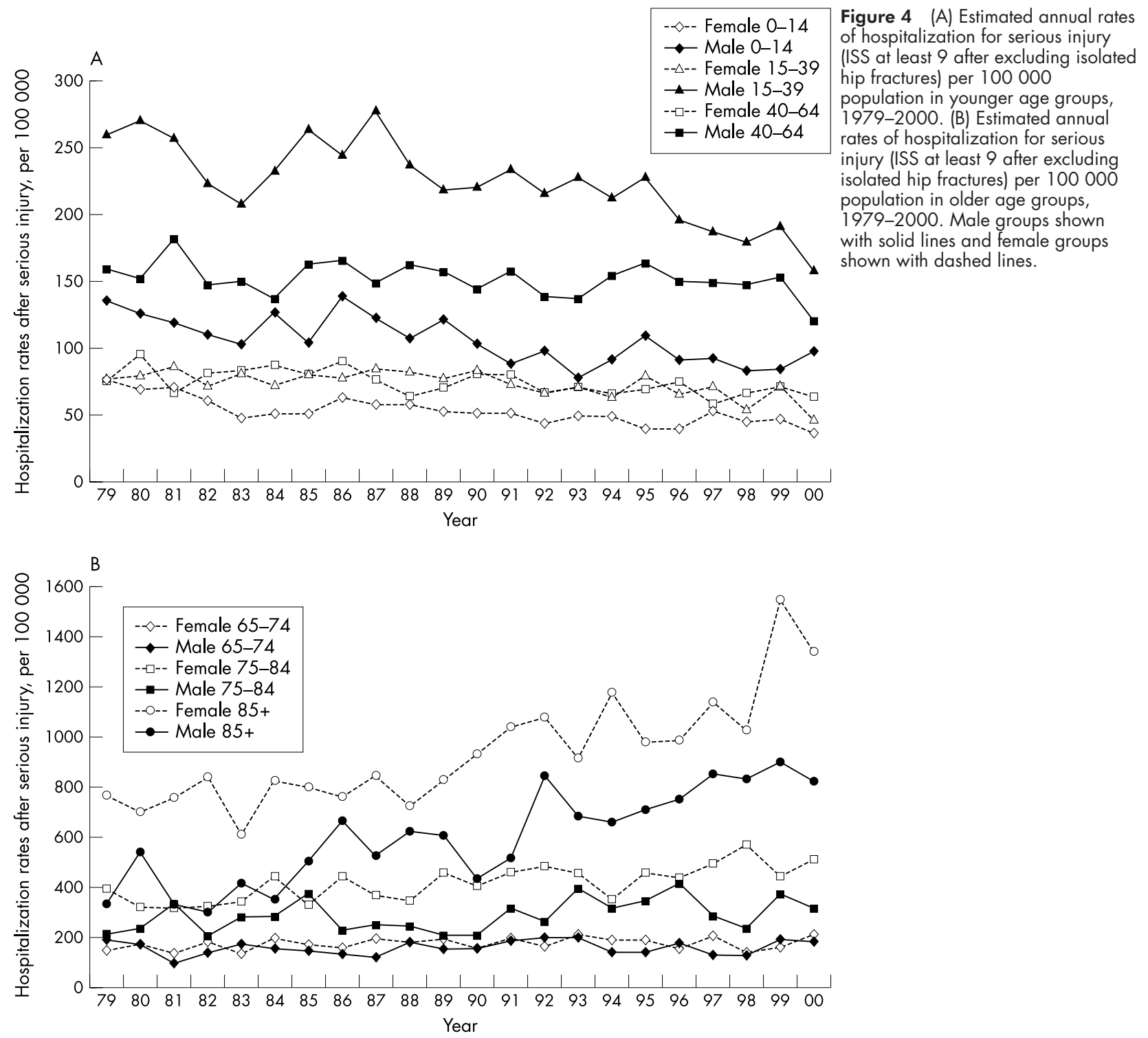

aged less than 40 years and has been relatively constant in the middle aged, while in the oldest age groups the rates increased, especially for women. Among the patients who had serious injuries, the proportion of patients aged 65 and older more than doubled (14\% in 1979 and $33 \%$ in 2000), while the proportion of patients aged less than 40 decreased by $30 \%$ (64\% in 1979 and $45 \%$ in 2000).

The availability of E codes in the NHDS data has increased over time from only $9 \%$ in 1979 , and $36 \%$ in 1990 , to $66 \%$ in 2000. Among patients with recorded E codes in 2000, falls accounted for $48 \%$ of admissions $(36 \%$ for age under $15,15 \%$ for ages $15-19,17 \%$ for ages $20-39,42 \%$ for ages $40-64,64 \%$ for ages $65-74,80 \%$ for ages $75-84$, and $84 \%$ for ages 85 and older), while motor vehicle collisions were involved in $17 \%$ of admissions $(17 \%, 33 \%, 28 \%, 20 \%, 15 \%, 6 \%$, and $3 \%$, respectively). However, falls were the mechanism of injury in only $39 \%$ of the serious injuries, while motor vehicle collisions were the mechanism of injuries in $28 \%$ of the serious injuries.

\section{DISCUSSION}

Our findings confirm that the results obtained in the state of Maine by Clark and $\mathrm{Chu}^{2}$ were representative of the United States as a whole: trauma can no longer be considered a "young person's disease", and trauma care systems are now often dealing with injuries in the older population.
Some of the differences over time may be attributed to changes in the age distribution of the US population: the proportion of the male population under the age of 40 has fallen from $66.2 \%$ in 1979 down to $59.7 \%$ in 2000 , while the proportion of the female population over aged 65 and older has risen from $13.0 \%$ to $14.4 \%$. However, these demographic changes are relatively small in comparison to the trends we have shown. Some of the change has also likely resulted from a decrease in the use of inpatient hospitalization for less severe injuries: moderate injuries that formerly resulted in hospital admission may be more often treated in an outpatient setting, and the length of stay for cases hospitalized may also have been shortened. However, the finding of decreased rates of serious injury in the younger population and increased rates in the older population are similar to changes in motor vehicle fatalities over this time, ${ }^{10}$ and suggest that preventive strategies have been less effective in the oldest age groups or that the preventive focus has been more on younger than older people. Although the outcomes of seriously injured elderly patients have varied among studies, ${ }^{11-13}$ it is obvious that injury prevention is preferable to expensive medical care due to severe injuries. ${ }^{14}$

Thurman and Guerrero analyzed traumatic brain injury using NHDS data, and also found decreasing rates of hospitalization with greater decreases in younger age groups. ${ }^{15}$ They found an increase in the incidence of severe 
injuries (AIS 4 or greater), but this finding was of uncertain significance due to a relatively large number of injuries of unknown severity in earlier years. These authors did not report any simultaneous stratification by age and severity.

The cost of caring for patients aged 65 and older with injuries (as well as other conditions) is borne largely by taxpayers through the Medicare system. Some reduction in hospital days appears to have been accomplished over the past decade as a result of changes in Medicare reimbursement for skilled nursing facility (SNF) stays. This can be attributed to federal legislation that has fostered the development of SNF beds in nursing homes. ${ }^{16}{ }^{17}$ The referral to SNF of patients ineligible for Medicare benefits (primarily those below the age of 65) has been much less common. Whether the use of SNF has indeed reduced the cost of care after injury, and the difference in SNF referrals between men and women, are areas requiring further study.

As a related issue, the use of hospital length of stay as a surrogate for costs clearly must be modified when dealing with the US population aged 65 and older. Efforts to predict length of stay among injured patients ${ }^{18-20}$ should allow for the fact that discharge from a hospital to a SNF in this age group is now encouraged by the Medicare fee structure. Ideally, predictive models should measure length of stay in SNF as well as in hospitals. However, even with an accurate measurement of length of stay, some of the costs generated in SNF (and reimbursed by Medicare) may be difficult to determine. ${ }^{21}$

Falls are the leading cause of injury death in older people, while motor vehicle collision is the leading cause under age $65 .{ }^{22}$ Our analysis of the E code data for the year 2000 also shows that falls account for a much higher proportion of total hospitalizations in the old than in the young. Fall injury occurs most frequently at home and in residential institutions, and a large body of evidence shows the effectiveness of fall prevention programs in these settings. ${ }^{23-25}$ Thus, priority should be given to promoting fall prevention programs, including comprehensive fall risk assessment and multidisciplinary intervention such as exercise programs (incorporating muscle strengthening and balance training), behavioral and educational programs, environmental modification, cessation of psychotropic medication, and use of hip protectors. ${ }^{26}$ The incidence of hip fractures may also be reduced by moderate levels of physical activity, ${ }^{27}$ combined hormone replacement therapy in women, ${ }^{28}$ and treatments to prevent osteoporosis. ${ }^{29}{ }^{30}$

Although not as frequent as falls, motor vehicle collisions represent a significant proportion of injuries in the older population. ${ }^{22}$ Stevens and Dellinger have recently shown that there are differences in mortality from motor vehicle collisions among different races and ethnicities, and that the death rate from motor vehicle collisions is much higher than from falls among older black men in the US. ${ }^{31}$ In general, motor vehicle occupants aged 65 and older have the highest proportion of safety belt usage, ${ }^{32}$ although certainly this proportion might be further improved through education and legislation. Air bags may help protect the older driver or passenger from injury in a crash, and side as well as frontal air bags would be particularly helpful for this group that sustains an increased number of side impact collisions. ${ }^{33}{ }^{34}$ The independence that the automobile allows is highly valued at all ages, and laws restricting older drivers might be difficult for this growing segment of the population to accept. However, many older drivers already limit their exposure by driving less often and avoiding complicated situations; this trend should at least be encouraged by development and improvement of mass transit or ride sharing programs.

There are several limitations in our study. The NHDS data are a sample, aggregated from different states. Even though it is expected that different states may have different priorities given the available resources and different rates of aging, the unavailability of state level information did not allow us to analyze the trends in each state. The sample design for NHDS

\section{Key points}

- Over the past 20 years, the number of young males hospitalized after injuries in the USA has decreased dramatically.

- Women aged 65 and older are now the group most frequently admitted to hospitals after injury.

- Most injured patients over aged 65 and older were formerly discharged home, but now most are discharged to long term care facilities.

- The institutional cost of injuries for older patients remains high, so that injury prevention in this age group is increasingly important.

changed somewhat in 1988, which may affect comparison of the estimates before and after this year'; however, the continuation of the same trends before and after suggests that this difference is minimal. Moreover, because NHDS is a sample, the estimates are subject to rounding and measurement error, which are in the range of $4 \%-5 \%$ for the subpopulation estimates in any given year. However, random sampling variation should not affect the trends seen with multiple observations over time.

Other potential limitations are related to ICD-9-CM coding changes during the 20 year span of this study. These may have affected injury severity scoring somewhat, although there were relatively few cases that could not be mapped in our study. ICDMAP-90 was designed for use with the 1990 version of the ICD-9-CM codes, essentially at the midpoint of our study, and the ISS has always been calculated from the same (older) version of the AIS. There has been no subsequent revision of ICDMAP-90, and it seems unlikely that enough change in the ICD-9-CM has occurred to affect our simple stratification using one value of ISS. Likewise, we have not found that the ICDMAP-90 options for handling unknowns and equivocal severities make much difference in crude stratifications.

In conclusion, this study found that the number of hospital admissions after injuries has decreased dramatically over the past two decades, especially for young males. Older patients now comprise a large proportion of the injured patients requiring hospitalization in the United States, and trauma systems must adapt to this change. ${ }^{2}$ Since morbidity in this age group results in significant medical costs and decreasing quality of life, increasing attention should be given to the prevention of injuries in this growing population.

\section{ACKNOWLEDGEMENTS}

This article was supported in part by a research fellowship from the Uehara Memorial Foundation (Dr Shinoda-Tagawa), and by grant \#R49/CCR115279-04 from the National Center for Injury Prevention and Control (Dr Clark). The opinions of the authors expressed in this article are not necessarily those of the funding agencies.

The authors also express appreciation to Dr David Hemenway, who reviewed a preliminary version of the manuscript and suggested improvements.

\section{Authors' affiliations}

T Shinoda-Tagawa, D E Clark, Harvard Injury Control Research Center, Boston

\section{REFERENCES}

1 Trunkey DD. Trauma. Sci Am 1983;249:28-35

2 Clark DE, Chu MK. Increasing importance of the elderly in a trauma system. Am J Emerg Med 2002;20:108-11.

3 Centers for Disease Control and Prevention. NHDS data. Available at: ftp://ftp.cdc.gov/pub/Health_Statistics/NCHS/Datasets/NHDS (accessed 11 December 2002).

4 Centers for Disease Control and Prevention. NHDS description. Available at: http://www.cdc.gov.nchs/data/series/sr_01/ sr_01_039.pdf (accessed 11 December 2002) 
5 Baker SP, O'Neill B, Haddon WJ, et al. The injury severity score: a method for describing patients with multiple injuries and evaluating emergency care. J Trauma 1974; 14:187-96.

6 MacKenzie EJ, Steinwachs DM, Shankar B. Classifying trauma severity based on hospital discharge diagnoses. Validation of an ICD-9CM to AIS-85 conversion table. Med Care 1989;27:412-22.

7 Anonymous. Recommended framework for presenting injury mortality data. MMWR Morb Mortal Wkly Rep 1997;46: 1-30.

8 Centers for Disease Control and Prevention. Wonder. Available at: http://wonder.cdc.gov/census.html (accessed 11 December 2002) Guria JC. Length of hospitalization - an indicator of social costs of disabilities from traffic injuries. Accid Anal Prev 1990;22:379-89.

10 US Department of Transportation NHTSA. Traffic safety facts 2000: a compilation of motor vehicle crash data from the Fatality Analysis Reporting System and the General Estimates System. Washington, DC: USDOT, 2001

11 Oreskovich MR, Howard JD, Copass MK, et al. Geriatric trauma: injury patterns and outcome. J Trauma 1984;24:565-72

12 Shabot MM, Johnson CL. Outcome from critical care in the "oldest old" trauma patients. J Trauma 1995:39:254-9.

13 Kilaru S, Garb J, Emhoff T, et al. Long-term functional status and mortality of elderly patients with severe closed head injuries. J Trauma 1996:41:957-63.

14 American College of Surgeons Committee on Trauma. Resources for optimal care of the injured patient: 1999. Chicago: ACS, 1999.

15 Thurman D, Guerrero J. Trends in hospitalization associated with traumatic brain injury. JAMA 1999:282:954-7.

16 Laliberte L, Mor V, Berg K, et al. Impact of the Medicare Catastrophic Coverage Act on nursing homes. Milbank Q 1997;75:203-33.

17 Lubitz J, Greenberg LG, Gorina Y, et al. Three decades of health care use by the elderly, 1965-1998. Health Aff (Millwood) 2001;20:19-32.

18 Siegel JH, Shafi S, Goodarzi S, et al. A quantitative method for cost reimbursement and length of stay quality assurance in multiple trauma patients. J Trauma 1994;37:928-37.

19 Rutledge R, Osler T. The ICD-9-based illness severity score: a new model that outperforms both DRG and APR-DRG as predictors of survival and resource utilization. J Trauma 1998;45:791-9.

20 Clark DE, Ryan LM. Concurrent prediction of hospital mortality and length of stay from risk factors on admission. Health Serv Res 2002; 37:631-45

21 Welch WP. What does Medicare pay for? Disentangling the flow of funds to health care providers. Health Aff (Millwood) 1998;17:184-97.
22 Centers for Disease Control and Prevention. WISQARS leading causes of death reports, 1999-2000. Available at: http:// webapp.cdc.gov/sasweb/ncipc/leadcaus 10.html (accessed 11 December 2002).

23 American Geriatrics Society, British Geriatrics Society, and American Academy of Orthopaedic Surgeons Panel on Falls Prevention. Guideline for the prevention of falls in older persons. J Am Geriatr Soc 2001;49:664-72

24 Gillespie LD, Gillespie WJ, Robertson MC, et al. Interventions for preventing falls in elderly people. Cochrane Database Syst Rev 2001;CD000340.

25 Robertson MC, Campbell AJ, Gardner MM, et al. Preventing injuries in older people by preventing falls: a meta-analysis of individual-level data. J Am Geriatr Soc 2002;50:905-11.

26 Parker MJ, Gillespie LD, Gillespie WJ. Hip protectors for preventing hip fractures in the elderly. Cochrane Database Syst Rev 2001:CD001255.

27 Feskanich D, Willett W, Colditz G. Walking and leisure-time activity and risk of hip fracture in postmenopausal women. JAMA 2002;288:2300-6

28 Writing Group for the Women's Health Initiative Investigators. Risks and benefits of estrogen plus progestin in healthy postmenopausal women. Principal results from the Women's Health Initiative Randomized Controlled Trial. JAMA 2002;288:321-33.

29 NIH Consensus Development Panel. Osteoporosis prevention, diagnosis, and therapy. JAMA 2001;285:785-95.

30 Royal College of Physicians. Osteoporosis clinical guidelines: summary and recommendation in 1999. Available at: http:// www.rcplondon.ac.uk/files/osteosummary.pdf, updated in 2001 (http://www.rcplondon.ac.uk/pubs/wp osteo update.htm).

31 Stevens JA, Dellinger AM. Motor vehicle and fall related deaths among older Americans 1990-98: sex, race, and ethnic disparities. Inj Prev 2002;8:272-5

32 Nelson DE, Bolen J, Kresnow M. Trends in safety belt use by demographics and by type of state safety belt law, 1987 through 1993. Am J Public Health 1998:88:245-9.

33 Viano DC, Culver CC, Evans L, et al. Involvement of older drivers in multivehicle side-impact crashes. Accid Anal Prev 1990;22:177-88.

34 Siögren $\mathbf{H}, B$ iörnstig $U$, Eriksson $A$, et al. Elderly in the traffic environment: analysis of fatal crashes in northern Sweden. Accid Anal Prev 1993:25:177-88.

Click on the "Top 10 Papers" button on the homepage

to see which are the best read articles each month

www.injuryprevention.com 